\title{
APLASIA ERITROIDE PURA SECUNDARIA A EMBARAZO: REPORTE DE UN CASO Y REVISIÓN DE LA LITERATURA
}

\section{Pure red-cell aplasia secondary to pregnancy: Case report and review of the literature}

Juan Felipe Herrera-Quintana, M. D. ${ }^{1}$; Ana Carolina Rojas-Figueroa, M. D. ${ }^{2}$; Rafael Leonardo Aragón-Mendoza, M. D. ${ }^{3}$; Roberto Gallo-Roa, M.D. ${ }^{4}$; Marcos Fidel Castillo-Zamora, M.D. ${ }^{4}$

Recibido: 16 de mayo de 2020/Aceptado: 18 de noviembre de 2020

\section{RESUMEN}

Objetivo: reportar el caso de una aplasia eritroide pura secundaria al embarazo y hacer una revisión de la literatura sobre el diagnóstico, tratamiento y pronóstico materno y perinatal.

Materiales y métodos: se presenta el caso de una paciente de 24 años, con embarazo de 34 semanas, remitida a un hospital público de referencia regional por anemia en estudio; se realiza biopsia de médula ósea sobre la que se hace diagnóstico de aplasia eritroide pura asociada al embarazo. Recibe manejo con transfusiones seriadas de glóbulos rojos; se realiza cesárea a término, con recién nacido sano; en su puerperio presenta estabilidad de los valores de hemoglobina. Se realizó búsqueda bibliográfica en las bases de datos electrónicas de Medline vía

* Correspondencia: Juan Felipe Herrera Quintana, Carrera 8 \# 0-29 Sur, Hospital Universitario de La Samaritana, Bogotá (Colombia). Teléfono 4077075.juanfe_quintana@hotmail.com

1 Médico, residente de Ginecología y Obstetricia, Universidad de La Sabana, Bogotá (Colombia).

2 Médico, residente de Ginecología y Obstetricia Universidad de La Sabana, Bogotá (Colombia).

3 Médico, ginecobstetra, Medicina materno-fetal, Hospital Universitario de La Samaritana, Bogotá (Colombia).

4 Médico, ginecobstetra, Hospital Universitario de La Samaritana, Bogotá (Colombia).
PubMed, LILACS, SciELO y ScienceDirect, con los términos "embarazo", "aplasia pura de células rojas”, "pregnancy” y “pure red-cell aplasia”. Se incluyeron reportes de caso, series de casos y revisiones bibliográficas en inglés y español, desde enero de 1999 a enero de 2020, de pacientes gestantes con aplasia eritriode pura. Se tomó información sobre el diagnóstico, tratamiento y pronóstico materno y perinatal. Tres autores seleccionaron los estudios por título y resumen. Se hace síntesis descriptiva. Resultados: se identificaron 828 títulos, de los cuales 818 fueron descartados luego de revisar los criterios de inclusión. Se incluyeron diez artículos: seis reportes de casos, tres reportes de caso con revisión de la literatura, un reporte de caso en la modalidad de poster, para un total de 10 casos reportados. El diagnóstico se basó en bajos niveles de hemoglobina y compromiso de la línea eritriode en la biopsia de médula. El tratamiento en transfusiones de glóbulos rojos y el pronóstico materno-fetal fueron buenos.

Conclusión: el diagnóstico de la aplasia eritroide pura en el embarazo requiere biopsia de médula. El pronóstico materno-perinatal es bueno, con soporte transfusional. Se requieren más estudios para eva- 
luar la seguridad y eficacia de los corticosteroides para esta entidad en el embarazo.

Palabras clave: embarazo; aplasia pura de células rojas.

\section{ABSTRACT}

Objective: To report a case of pure red-cell aplasia secondary to pregnancy and to conduct a review of the literature regarding diagnosis and treatment, as well as maternal and perinatal prognosis.

Materials and methods: This is the case of a 24-year-old patient at 34 weeks of gestation, referred to a regional public referral hospital due to anemia. Bone marrow biopsy was performed, leading to the diagnosis of pregnancy-related pure red-cell aplasia. The patient received serial red blood cell transfusions. Delivery by Cesarean section at term resulted in a healthy newborn. Hemoglobin values remained stable during the postoperative period. A literature search was conducted in Medline via PubMed, LILACS, SciELO and ScienceDirect using the terms "pregnancy" and "pure red-cell aplasia”. Case reports, case series and literature reviews in English and Spanish published between January 1999 and January 2020 that report pregnant women with pure red-cell aplasia were included. Information on diagnosis, treatment and maternal and perinatal prognosis was collected. Three of the authors selected the studies by title and abstract; A descriptive synthesis is provided.

Results: Overall, 828 titles were identified; of these, 818 were discarded after reviewing the inclusions criteria. Ten articles were included: six case reports, three case reports with literature review, and one case report in the poster modality, for a total number of 10 reported cases. Diagnosis was based on low hemoglobin levels and compromised erythroid cell line in bone marrow biopsy. Treatment consists of red blood cell transfusions, with good maternal and fetal prognosis.

Conclusion: Diagnosis of pure red-cell aplasia during pregnancy requires bone marrow biopsy. With transfusion support, maternal perinatal prognosis is good. Further studies are required to assess the safety and efficacy of steroid use in this pregnancy-related condition.

Key words: Pregnancy; pure red-cell aplasia.

\section{INTRODUCCIÓN}

La aplasia eritroide pura (AEP) es un trastorno hematológico descrito por primera vez en 1922, que se caracteriza por anemia severa debido a depresión selectiva en la eritropoyesis de la médula ósea. Existe una forma congénita o síndrome de Diamond Blackfan, que se presenta en cinco casos por un millón de nacidos vivos, caracterizada por malformaciones como dismorfismo craneofacial, anomalías urogenitales, entre otros, hasta en un tercio de todos los pacientes; y una forma adquirida (AEPA), la cual está asociada a múltiples causas infecciosas, autoinmunes, neoplásicas, entre otras, donde no se encuentra reportada una frecuencia estimada en su presentación (1).

El diagnóstico de la aplasia eritroide está dado por una anemia normocítica normocroómica, asociada a reticulocitopenia en la sangre periférica y eritoblastos ausentes o poco frecuentes en la biopsia de médula ósea, con precursores intactos de plaquetas y leucocitos; su tratamiento corresponde al soporte transfusional asociado al manejo específico de la etiología subyacente (1). Se han utilizado algunos tratamientos farmacológicos entre los que se encuentran con mejor eficacia la ciclosporina (2), y los corticosteroides (3).

La fisiopatología en el embarazo aún no está clara. Se ha propuesto que las progestinas juegan un papel en la génesis, de tal forma que los cambios hormonales durante el embarazo desencadenan un mecanismo autoinmune en pacientes predispuestas que lleva a inhibición de colonias eritroides, lo que sugiere una respuesta autoinmune humoral (4-5), y la presencia en la sangre periférica de la madre y células placentarias de un factor inhibidor que afecta la eritropoyesis y diferenciación eritroide (6). El diagnóstico de la AEP en el embrazo es por descarte y los hallazgos de la biopsia de médula ósea 
y la recuperación de los niveles de hemoglobina en pocas semanas posteriores al parto soporta aún más el diagnóstico (6). El tratamiento estaría basado en múltiples transfusiones de hemoderivados durante su periodo gestacional para mantener los niveles de hemoglobina, con riesgo de reacciones secundarias. Como tratamiento adicional (al uso de hemoderivados), en reportes de caso publicados hasta 2003 se había descrito el uso de corticoides y ciclofosfamida (6), sin embargo, es poca la información sobre su seguridad y el pronóstico fetal y perinatal de la condición posterior a esta revisión.

Se presenta un caso de AEP asociada al embarazo y se realiza una revisión de la literatura con el objetivo de determinar el diagnóstico, tratamiento y pronóstico materno y perinatal en pacientes gestantes con aplasia eritroide pura secundaria al embarazo, tratado con transfusión de hemoderivados.

\section{REPORTE DE CASO}

Paciente de 24 años, G1P0, con gestación de 34 semanas calculadas por ultrasonido de primer trimestre. Ingresa referida de la consulta externa del servicio de hematología del Hospital Universitario de La Samaritana, institución de alta complejidad, y centro de referencia de pacientes de la región central del país, pertenecientes al régimen subsidiado por el Estado en el Sistema General de Seguridad Social en Colombia, para estudio de síndrome anémico; durante la gestación había recibido transfusión de 11 unidades de glóbulos rojos empaquetados.

No se identificaron antecedentes patológicos, quirúrgicos, tóxico/alérgicos familiares. Había recibido micronutrientes en la gestación actual. $\mathrm{Al}$ examen físico se observó buen estado general, alerta, con palidez mucocutánea. Tensión arterial: 102/74 mmHg, frecuencia cardiaca: 76 latidos por minuto, temperatura: $36,2^{\circ} \mathrm{C}$ y saturación de oxígeno de $92 \%$ al ambiente, abdomen con altura uterina de 31 centímetros con feto único en presentación de pelvis con frecuencia cardiaca fetal de 147 latidos por minuto. Sin otros datos positivos, la paciente se hospitaliza para estudios comple- mentarios de anemia severa sin etiología clara, con vigilancia materno-fetal y tratamiento de la misma; el hemograma de ingreso con hemoglobina 4,9g/ $\mathrm{dl}$, hematocrito $14 \%$, volumen corpuscular medio $86 \mathrm{fL}$ y hemoglobina corpuscular media $28 \mathrm{pg}$, con leucocitos $6,71 \times 10^{\wedge} 3 / \mathrm{uL}$, con un diferencial leucocitario normal, plaquetas $203 \times 10^{\wedge} 3 / \mathrm{uL}$. Velocidad de sedimentación globular $42 \mathrm{~mm}$, el extendido de sangre periférica con eritrocitos con anisocitosis, policromatofilia ligera, hipocromía ligera, leucocitos y plaquetas con morfología normal. Bilirrubina total: $0,88 \mathrm{mg} / \mathrm{dl}$, bilirrubina directa: $0,07 \mathrm{mg} / \mathrm{dl}$, vitamina B12: 186 pg/L (niveles normales [NN]: 99$526 \mathrm{pg} / \mathrm{L}$ ), ácido fólico: 18,6 ng/ml (NN: 1,4-20,7), reticulocitos: 0,40\% (NN 0,4-1,5\%), Coombs directo negativo, ferritina: 693,8 ng/ml (NN 0-116 ng/ml), transferrina: 208 mg/dl (NN: 200-530), con función renal y hepática normales. A la valoración fetal con monitoreo fetal reactivo, ultrasonido obstétrico que evidencia embarazo de 34,6 semanas por biometría, sin malformaciones anatómicas, con peso fetal estimado de $2.344 \mathrm{~g}$, percentil $42 \%$, placenta normo-inserta, índice de líquido amniótico de 13,5 cm, doppler feto-placentario y velocidad pico de arteria cerebral dentro de límites normales. Se decide realizar aspirado y biopsia de médula ósea. El aspirado de médula ósea mostró celularidad normal para la edad, maduración adecuada en línea mieloide y linfoide con ausencia total de precursores de la línea roja, se hace impresión diagnóstica de hipoplasia eritroide (figura 1). Se practicó simultáneamente biopsia de médula ósea que evidenció celularidad variable del 10-30\%, con hematopoyesis de las tres líneas celulares; relación mieloide-eritroide 3:1, la línea mieloide con adecuada maduración y morfología, la línea eritroide marcadamente disminuida (CD71 < $5 \%$ ). Megacariocitos presentes, hasta seis por campo, de alto poder sin alteraciones morfológicas, sugestivo de aplasia eritroide pura asociada al embarazo. Se indica la transfusión de glóbulos rojos empaquetados. Se indica continuar con vigilancia materno-fetal hospitalaria, realizando hemoglobinas seriadas, monitoreo fetal diario y tratamiento con 


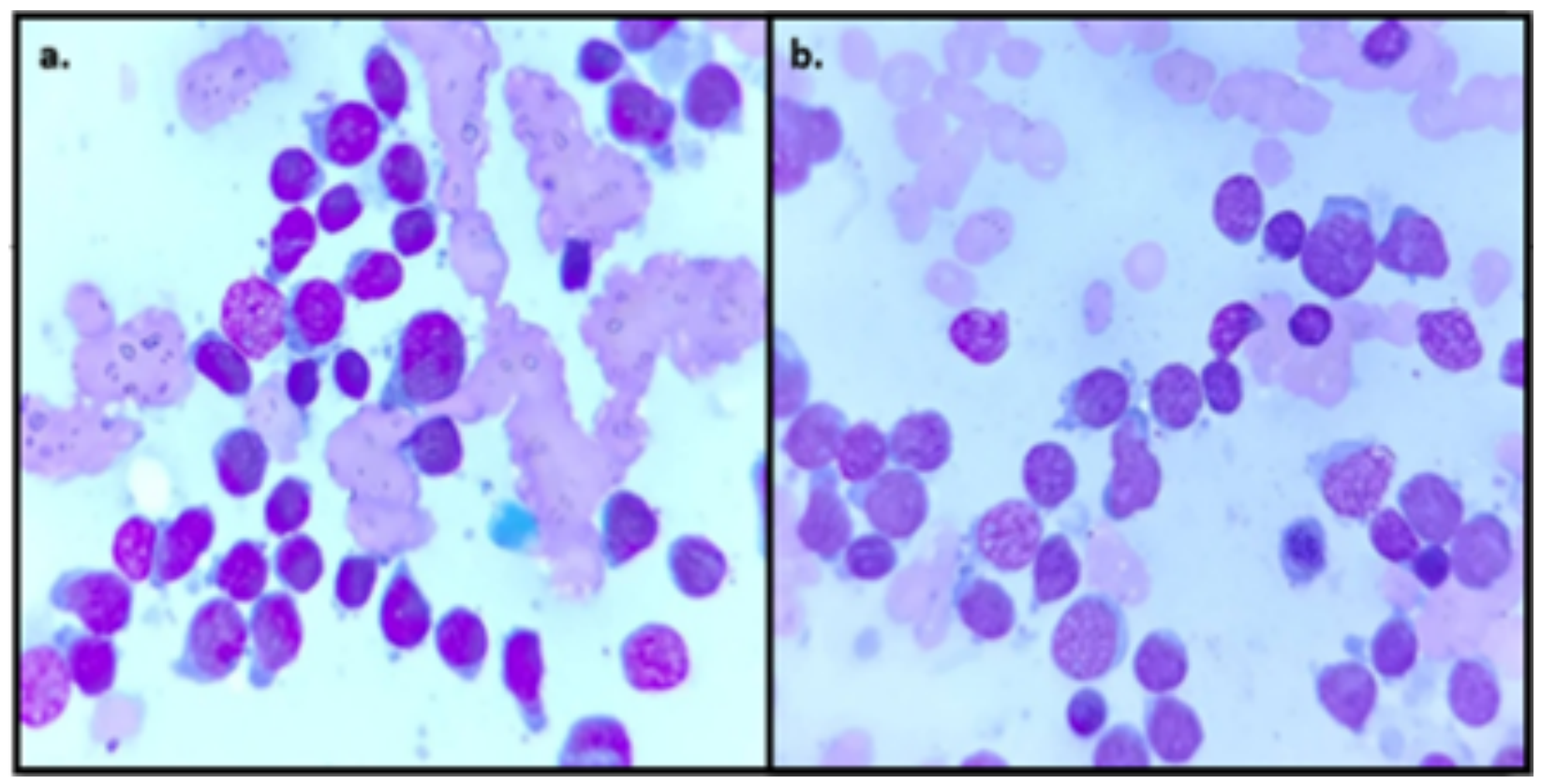

Figura 1. Aspirado de médula ósea: láminas a y b (100X): se observa celularidad normal; precursores de la línea mieloide y linfoide normales en número y morfología. Ausencia total de precursores de línea roja. Aplasia eritroide

soporte transfusional seriado para mantener niveles de hemoglobina mayor a $7 \mathrm{~g} / \mathrm{dl}$.

Se realiza junta multidisciplinaria médico-quirúrgica con los servicios de hematología, ginecología, medicina materno-fetal y neonatología, donde se valoran los paraclínicos previos a la hospitalización. La paciente tiene cariotipo euploide 46XX, por lo que se descarta etiología de origen genético; tampoco hay antecedentes que orienten a etiología infecciosa, autoinmune, tumoral (timoma) o por medicamentos, por lo que se considera que corresponde a una AEPA asociada al embarazo. Se realiza cesárea en la semana 38 por feto en presentación de pelvis con recién nacido sano, con un peso de 2.775 g, APGAR: 8-9-10. La paciente evoluciona adecuadamente en su posoperatorio, con estabilidad hemodinámica y paraclínicos con hemoglobina de control de $10 \mathrm{~g} / \mathrm{dl}$, hematocrito $29 \%$, con posterior egreso, requiriendo un total de 8 unidades de glóbulos rojos empaquetados transfundidas durante la estancia hospitalaria (6 unidades durante seguimiento hospitalario y 2 unidades intraquirúrgico). A su control posoperatorio en consulta externa asiste asintomática, con estabilidad hemodinámica y adecuada evolución de su puerperio, con una hemoglobina de control de $6,3 \mathrm{~g} / \mathrm{dl}$ y hematocrito del $18 \%$; se indica la transfusión de 2 unidades de glóbulos rojos empaquetados con hemoglobina posterior en $8,0 \mathrm{~g} / \mathrm{dl}$, completando así un total de 21 unidades de glóbulos rojos empaquetados durante su gestación; a los 10 meses de seguimiento, en control con hematología, no había requerido nuevas transfusiones de hemoderivados.

Aspectos éticos. Se solicitó autorización a la paciente, con consentimiento informado escrito, a través de la oficina de investigación y comité de ética médica del Hospital Universitario de La Samaritana, para publicar el caso y material fotográfico, el cual fue tomado por los autores.

\section{MATERIALES Y MÉTODOS}

Se realizó una búsqueda bibliográfica en las bases de datos electrónicas de: Medline vía PubMed, LILACS, SciELO y ScienceDirect con los términos: "embarazo", "aplasia pura de células rojas", "pregnancy" y "pure red-cell aplasia”. Los criterios 
de inclusión por tipo de estudio fueron: reportes y serie de casos, cohortes y revisiones; por tipo de población: mujeres gestantes con diagnóstico de aplasia eritroide pura, desde enero de 1999 a enero de 2020 en español e inglés; se evaluaron aspectos relacionados con las características del estudio: país donde se presentó, diagnóstico, edad gestacional al momento del diagnóstico, valores de hemoglobina, hallazgos en la biopsia de médula ósea, marcadores inmunohistoquímicos o genéticos realizados, otros métodos diagnósticos utilizados para detectar la posible causa. En cuanto al tratamiento: tipo de tratamiento transfusional, farmacológico, inmunológico o de otro tipo. Pronóstico perinatal: peso del recién nacido, comorbilidades, edad gestacional al momento del parto, tratamiento médico. Pronóstico materno: otras comorbilidades, evolución a los 6 y 12 meses desde el punto de vista de recuperación de la anemia o necesidad de transfusiones. Tres autores seleccionaron los artículos que fueran series de casos o revisiones de la literatura, inicialmente por título y resumen, publicados en inglés y español, desde enero 1999 a enero 2020. La información se extrajo en un archivo de excel. Se hace síntesis narrativa de los hallazgos.

\section{RESULTADOS}

Se identificaron 828 títulos, de los cuales 818 fueron descartados luego de revisar los criterios de inclusión (figura 2). Finalmente, se incluyeron

\section{Figura 2.}

Flujograma de selección de estudios

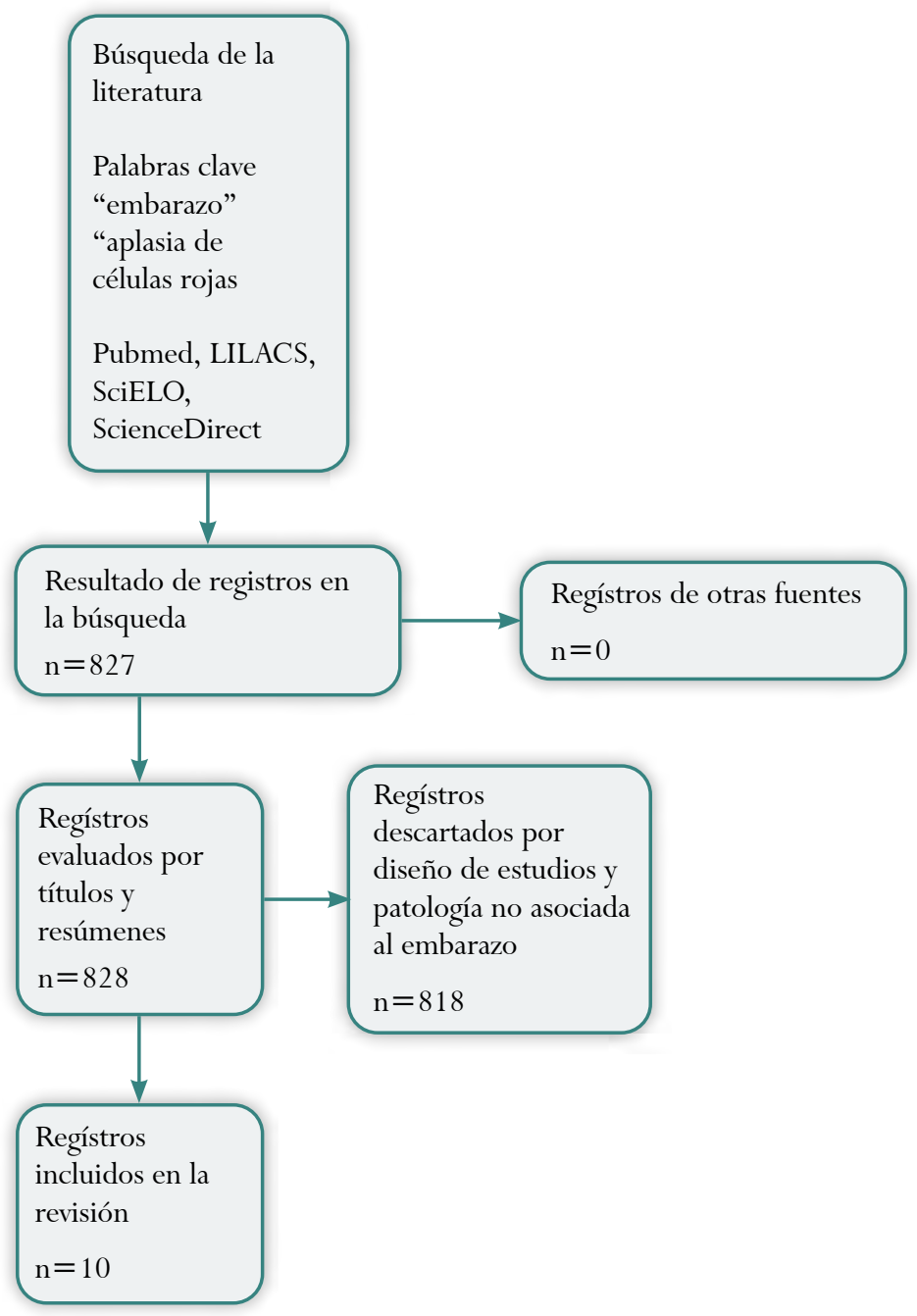


diez estudios relacionados con anemia aplásica eritroide pura asociada a embarazo: seis reportes de casos (4,7-11,) tres reportes de caso con revisión de la literatura $(6,12,13)$, un reporte de caso en la modalidad de poster (5), para un total de 10 casos reportados (tabla 1).
De los 10 casos reportados, cinco se presentaron entre los 20 y 29 años (4,7-10), cuatro casos se presentaron entre los 30 y 39 años $(5,6,12,13)$, y un caso no registra la edad de la paciente (11); seis casos fueron primigestantes $(5,7-10,12)$, cuatro casos multíparas $(4,6,11,12)$.

Tabla 1.

Casos reportados de aplasia eritroide pura asociada a embarazo entre 2000 y 2020

\begin{tabular}{|c|c|c|c|c|c|c|c|c|c|c|c|c|}
\hline$\stackrel{5}{\frac{3}{3}}$ & 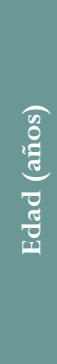 & 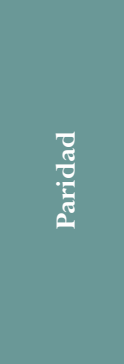 & 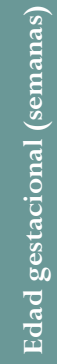 & 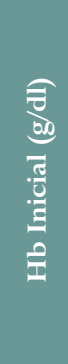 & 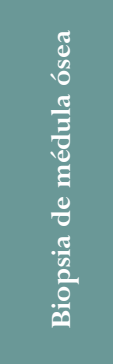 & $\begin{array}{l}\text { है } \\
\text { है } \\
\text { हूँ } \\
\text { हैं } \\
\text { है }\end{array}$ & 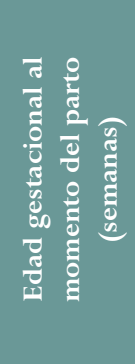 & 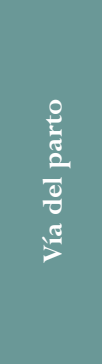 & 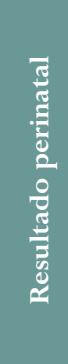 & 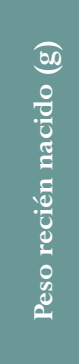 & 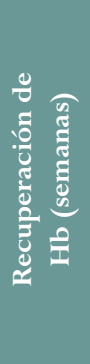 & $\begin{array}{l}0 \\
0 \\
0 \\
0 \\
0 \\
0 \\
0 \\
0 \\
0 \\
0 \\
0\end{array}$ \\
\hline $\begin{array}{c}\text { Ohno } \\
2002 \\
\text { Japón } \\
(10)\end{array}$ & 26 & G1P0 & 31 & 5.8 & $\begin{array}{c}\text { Aplasia } \\
\text { selectiva } \\
\text { de línea } \\
\text { eritroide }\end{array}$ & Transfusión & 34 & Cesárea & Vivo & 1631 & 12 & $\begin{array}{c}\text { Asociada } \\
\text { a hepatitis } \\
\text { de etiología } \\
\text { desconocida, } \\
\text { restricción de } \\
\text { crecimiento } \\
\text { intrauterino, } \\
\text { isoinmunización }\end{array}$ \\
\hline $\begin{array}{c}\text { Makino } \\
2003 \\
\text { Japón } \\
(12)\end{array}$ & 31 & G2A1 & 19 & 6 & $\begin{array}{c}\text { Aplasia } \\
\text { selectiva } \\
\text { de línea } \\
\text { eritroide }\end{array}$ & $\begin{array}{l}\text { Transfusión } \\
\text { Prednisona }\end{array}$ & 37 & Cesárea & Vivo & 2577 & 2 & \\
\hline $\begin{array}{l}\text { Chung } \\
2004 \\
\text { Corea } \\
(8)\end{array}$ & 28 & NR & 38 & 7.9 & $\begin{array}{c}\text { Aplasia } \\
\text { selectiva } \\
\text { de línea } \\
\text { eritroide }\end{array}$ & $\begin{array}{l}\text { Inmunoglo- } \\
\text { bulina } \\
\text { Metilpred- } \\
\text { nisolona } \\
\text { Prednisolona }\end{array}$ & A término & NR & Vivo & NR & 8 & $\begin{array}{c}\text { Asociado a } \\
\text { enfermedad } \\
\text { de Still }\end{array}$ \\
\hline $\begin{array}{c}\text { Choun- } \\
\text { dry } \\
2007 \\
\text { EE. UU. } \\
\quad(6)\end{array}$ & 33 & G3P2V2 & 14 & NR & $\begin{array}{c}\text { Aplasia } \\
\text { selectiva } \\
\text { de línea } \\
\text { eritroide }\end{array}$ & $\begin{array}{c}\text { Transfusión } \\
\text { Predniso- } \\
\text { lona }\end{array}$ & A término & $\begin{array}{c}\text { Cesá- } \\
\text { rea }\end{array}$ & Vivo & NR & 10 & $\begin{array}{c}\text { Antecedente } \\
\text { de } 2 \text { episodios } \\
\text { asociados a } \\
\text { aplicación de } \\
\text { medroxipro- } \\
\text { gesterona }\end{array}$ \\
\hline
\end{tabular}




\begin{tabular}{|c|c|c|c|c|c|c|c|c|c|c|c|c|}
\hline$\stackrel{\grave{3}}{\frac{1}{2}}$ & 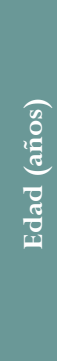 & 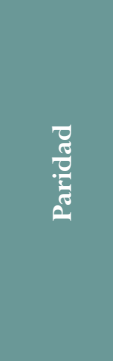 & 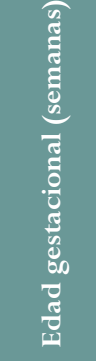 & 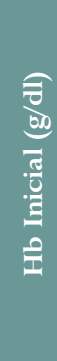 & 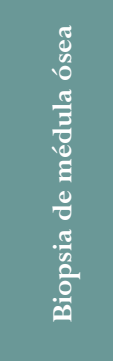 & 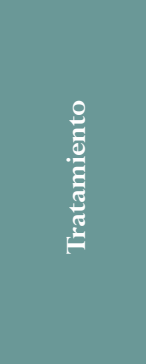 & 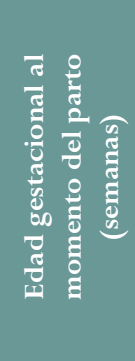 & 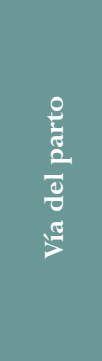 & 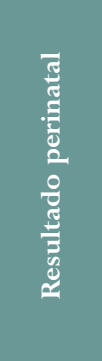 & $\begin{array}{l}\text { ब00 } \\
0 \\
\frac{0}{0} \\
\frac{0}{0} \\
\frac{5}{0} \\
\frac{0}{0} \\
0 \\
0 \\
0 \\
0\end{array}$ & 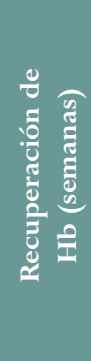 & 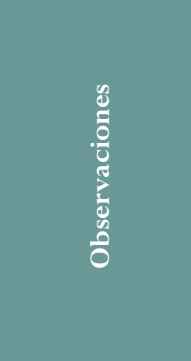 \\
\hline $\begin{array}{c}\text { Miller } \\
\text { EE. UU } \\
2008 \\
(11)\end{array}$ & NR & $\mathrm{G} 2 \mathrm{P} 1$ & NR & 3.2 & $\begin{array}{c}\text { Aplasia } \\
\text { selectiva } \\
\text { de línea } \\
\text { eritroide }\end{array}$ & Transfusión & A término & Vaginal & Vivo & NR & $\begin{array}{l}\text { Popar- } \\
\text { to }\end{array}$ & $\begin{array}{c}\text { Presentó nuevo } \\
\text { episodio en } \\
2 \text { gestaciones } \\
\text { posteriores }\end{array}$ \\
\hline $\begin{array}{l}\text { Kashap } \\
2010 \\
\text { India } \\
(4)\end{array}$ & 24 & G4P2A1 & 21 & 3.3 & $\begin{array}{c}\text { Aplasia } \\
\text { selectiva } \\
\text { de línea } \\
\text { eritroide }\end{array}$ & $\begin{array}{l}\text { Transfusión } \\
\text { Predniso- } \\
\text { lona }\end{array}$ & 37 & Vaginal & $\begin{array}{l}\text { Muerte } \\
\text { Fetal }\end{array}$ & 2650 & 4 & \\
\hline $\begin{array}{c}\text { Aggarwal } \\
2013 \\
\text { India (7) }\end{array}$ & 28 & G1P0 & $\begin{array}{l}15 \text { días } \\
\text { post- } \\
\text { parto }\end{array}$ & 3.2 & $\begin{array}{c}\text { Aplasia } \\
\text { selectiva } \\
\text { de línea } \\
\text { eritroide }\end{array}$ & Transfusión & $\begin{array}{c}\text { A } \\
\text { término }\end{array}$ & $\begin{array}{l}\text { Cesá- } \\
\text { rea }\end{array}$ & NR & NR & 6 & $\begin{array}{c}\text { Caso en } \\
\text { puerperio }\end{array}$ \\
\hline $\begin{array}{l}\text { Moussa } \\
2014 \\
\text { Egipto } \\
(9)\end{array}$ & 25 & G1P0 & 26 & 5.1 & NR & $\begin{array}{l}\text { Transfusión } \\
\text { Predniso- } \\
\text { lona }\end{array}$ & NR & NR & NR & NR & $\begin{array}{l}4 \text { (du- } \\
\text { rante } \\
\text { gesta- } \\
\text { ción) }\end{array}$ & $\begin{array}{l}\text { Asociado } \\
\text { a enfermedad } \\
\text { de Still }\end{array}$ \\
\hline $\begin{array}{l}\text { Matsui } \\
2017 \\
\text { Japón } \\
\text { (5) }\end{array}$ & 37 & G1P0 & 27 & NR & $\begin{array}{c}\text { Aplasia } \\
\text { selectiva } \\
\text { de línea } \\
\text { eritroide }\end{array}$ & Transfusión & 40 & Vaginal & Vivo & 2548 & NR & $\begin{array}{l}\text { Asociado a } \\
\text { timoma }\end{array}$ \\
\hline $\begin{array}{c}\text { Edahiro } \\
2019 \\
\text { Japón } \\
(13)\end{array}$ & 35 & G1P0 & 28 & 3.7 & $\begin{array}{c}\text { Aplasia } \\
\text { selectiva } \\
\text { de línea } \\
\text { eritroide }\end{array}$ & $\begin{array}{l}\text { Transfusión } \\
\text { Corticoides }\end{array}$ & 37 & Vaginal & Vivo & NR & 28 & $\begin{array}{c}\text { Presentó } \\
\text { nuevo episodio } \\
\text { en una gestación } \\
\text { posterior con } \\
\text { recién nacido a } \\
\text { término, tratada } \\
\text { con transfu- } \\
\text { siones }\end{array}$ \\
\hline
\end{tabular}

Diagnóstico: el diagnóstico se realizó en el primer trimestre en un caso (6), en el segundo trimestre en cinco casos $(4,5,9,12,13)$, tercer trimestre dos casos $(8,10)$, un caso durante el puperperio (7) y no se registró el momento del diagnóstico en un caso (11). Los niveles de hemoglobina variaron al momento del diagnóstico: cuatro casos con niveles menores de 5 $\mathrm{mg} / \mathrm{dl}(4,7,11,13)$, cuatro casos por encima de $5 \mathrm{mg} /$ $\mathrm{dl}(8-10,12)$, y no se reportaron niveles de hemoglobina en dos casos $(5,6)$. El diagnóstico confirmatorio se realizó con biopsia de médula ósea en nueve casos en los que se encontró aplasia selectiva de médula 
ósea sin compromiso de otras líneas celulares (48,10-13); en un caso, por decisión de la paciente, no se realizó biopsia de médula ósea (9). Existen casos reportados de anemia aplásica eritroide pura durante el embarazo, asociados a otras patologías, como enfermedad de Still y hepatitis no infecciosa, lo que dificultó su diagnóstico y la diferenciación de su etiología asociada a la gestación propiamente (8-10).

Tratamiento: de los casos reportados, cuatro se trataron únicamente con transfusión seriada de glóbulos rojos $(5,7,10,11)$; cinco casos recibieron manejo conjunto con transfusiones de glóbulos rojos y corticoides $(4,6,9,12,13)$; un caso fue tratado con administración de inmunoglobulina asociada a corticoides y transfusión de glóbulos rojos (8), sin reportar eventos adversos en ninguno de los casos. No se describen niveles de hemoglobina mínimos u óptimos para mantener durante la gestación. En nuestro caso, se definieron niveles de hemoglobina mayores a $7 \mathrm{~g} / \mathrm{dl}$ debido a que la Organización Mundial de la Salud (OMS) define una anemia severa menor a estos niveles con lo cual se puede aumentar la morbi-mortalidad perinatal asociada a anemia materna.

Pronóstico. En la presente revisión se evidenciaron adecuados resultados materno-perinatales. Se informa un total de siete recién nacidos a término (5-8,1113); se reportó un caso de recién nacido pretérmino con restricción de crecimiento intrauterino (10) y un óbito reportado por Kashap y Pradhan (4). En un estudio se consideró que el resultado fetal adverso en los casos de aplasia eritroide pura se puede dar si los niveles de hemoglobina maternos no son adecuados (7). Un caso no reportó resultado perinatal (9). Se reportaron cuatro casos con parto vaginal $(4,5,11,13)$, cuatro partos por cesárea $(6,7,10,12)$ y dos casos no reportaron vía del parto $(8,9)$.

Con respecto al pronóstico materno, en los reportes de caso no se reseñan muertes maternas debido a la anemia o complicaciones del parto. Se encontró recuperación de los niveles de hemoglobina en la totalidad de los casos; un caso con recuperación en menos de cuatro semanas (12), tres casos entre cuatro y ocho semanas de tratamiento $(4,7,8)$, dos casos con recuperación entre ocho y doce semanas $(6,10)$ con un rango hasta de 28 semanas para lograr recuperación total de niveles de hemoglobina (13); no se reportó tiempo de recuperación en tres casos $(5,9,11)$ y un caso presentó recuperación a las cuatro semanas de haber iniciado tratamiento durante la gestación (9). Se reportaron tres casos en los que la aplasia eritroide pura se presentó en gestaciones posteriores, por tanto, podría considerarse una vigilancia más estrecha en estas pacientes $(6,11,13)$.

\section{CONCLUSIÓN}

La aplasia eritroide pura asociada al embarazo es una entidad poco descrita en la literatura, su diagnóstico está basado en el descarte de otras etiologías y es confirmado por la biopsia de médula ósea. El tratamiento está basado en transfusiones de glóbulos rojos y el pronóstico materno y perinatal es bueno. Se requieren estudios que evalúen la eficacia y seguridad de los corticosteroides en esta condición en el embarazo.

\section{FUENTES DE FINANCIACIÓN}

Este proyecto no tuvo fuentes de financiación.

\section{REFERENCIAS}

1. Mangla A, Hamad H. Pure red cell aplasia. In: StatPearls. Treasure Island (FL): StatPearls Publishing; 2020. PMID: 31751023.

2. Means RT. Pure red cell aplasia. Blood. 2016; 128(21):2504-9. https://doi.org/10.1182/blood2016-05-717140

3. Sawada K, Fujishima N, Hirokawa M. Acquired pure red cell aplasia: Updated review of treatment. Br J Haematol. 2008;142(4):505-14. https://doi. org/10.1111/j.1365-2141.2008.07216.x

4. Kashyap R, Pradhan M. Maternal and fetal outcome in pregnancy-associated pure red cell aplasia. J Obstet Gynaecol. 2010;30(7):733-4. https://doi.org/10.310 9/01443615.2010.501919 
5. Matsui H, Umehara N, Shibata M, Kaneko K, Irie R, Yoshioka T, et al. A case of thymoma complicated pure red cell aplasia and candida funisitis during pregnancy. Placenta. 2017;57:323. https://doi.org/10.1016/j. placenta.2017.07.310

6. Choudry MA, Moffett BK, Laber DA. Pure red-cell aplasia secondary to pregnancy, characterization of a syndrome. Ann Hematol. 2007;86(4):233-7. https:// doi.org/10.1007/s00277-006-0211-4

7. Aggarwal S. Reversible pure red cell aplasia of pregnancy: A therapeutic challenge. J Obstet Gynecol India. 2013;63(2):138-9. https://doi.org/10.1007/ s13224-011-0069-9

8. Chung JW, Suh YJ, Song HJ, Choi JH, Park HS, Cho SR, et al. Pure red cell aplasia and adult-onset Still's disease. Clin Rheumatol. 2004;23(4):368-70. https:// doi.org/10.1007/s10067-004-0899-2

9. Moussa M, Hassan MF. Newly diagnosed adult-onset still's disease with pure red cell aplasia in pregnancy. Arch Gynecol Obstet. 2014;290(1):195-8. https:// doi.org/10.1007/s00404-014-3184-x

10. Ohno Y, Itakura A, Sano M, Mizutani S. Pure red cell aplasia and acute hepatitis during pregnancy. Gynecolic Obstet Investig. 2002;53:112-3. https://doi. org/10.1159/000053004

11. Miller AC, Rashid RM. Three episodes of acquired pure red cell aplasia restricted to pregnancy. J Perinat Med. 2008;36(3):270-1. https://doi.org/10.1515/ JPM.2008.041
12. Makino Y, Nagano M, Tamura K, Kawarabayashi T. Pregnancy complicated with pure red cell aplasia: A case report. J Perinat Med. 2003;31(6):530-4. https:// doi.org/10.1515/JPM.2003.082

13. Edahiro Y, Yasuda H, Ando K, Komatsu N. Self-limiting pregnancy-associated pure red cell aplasia developing in two consecutive pregnancies: Case report and literature review. Int J Hematol. 2020;111(4):579-84. https://doi.org/10.1007/s12185-019-02792-x

\section{CONTRIBUCIÓN DE LOS AUTORES}

Juan Felipe Herrera Quintana: búsqueda en bases de datos, análisis de información, redacción y revisión final del manuscrito.

Ana Carolina Rojas Figueroa: búsqueda en bases de datos, análisis de información, redacción y revisión final del manuscrito.

Rafael Leonardo Aragón Mendoza: búsqueda en bases de datos, análisis de información, redacción y revisión final del manuscrito.

Roberto Gallo Roa: búsqueda en bases de datos, redacción y revisión final del manuscrito.

Marcos Fidel Castillo Zamora: búsqueda en bases de datos, redacción y revisión final del manuscrito. 